\title{
The Relationship between Life Satisfaction and Risk Behaviors: A Cross-Cultural Analysis of Youth
}

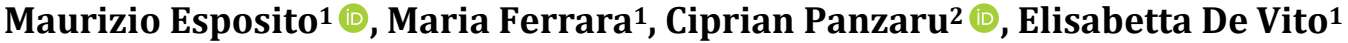 \\ ${ }^{1}$ Department of Human, Social and Health Sciences, University of Cassino and Southern Lazio, Cassino, Italy \\ ${ }^{2}$ Department of Sociology, West University of Timisoara, Timisoara, Romania \\ Email:m.esposito@unicas.it,m.ferrara@unicas.it,ciprian.panzaru@e-uvt.ro,devito@unicas.it
}

How to cite this paper: Esposito, M., Ferrara, M., Panzaru, C., \& De Vito, E. (2020). The Relationship between Life Satisfaction and Risk Behaviors: A Cross-Cultural Analysis of Youth. Advances in Applied Sociology, 10, 356-368.

https://doi.org/10.4236/aasoci.2020.109022

Received: August 16, 2020

Accepted: September 18, 2020

Published: September 21, 2020

Copyright $\odot 2020$ by author(s) and Scientific Research Publishing Inc. This work is licensed under the Creative Commons Attribution International License (CC BY 4.0).

http://creativecommons.org/licenses/by/4.0/

\begin{abstract}
This study investigates the relationship between life satisfaction and behavioral risky acts in youth and analyzes how this relationship may differ or be similar across two groups from two different regions at NUTS 3 level: Frosinonearea, in Italy, and Timisarea, in Romania. Even though both regions are quite similar in terms of population structure, they have a different historical background and are completely different in terms of labor market; however, their GDP per capita levels are similar. The analysis of the responses indicates that there is evidence to suggest that exposure to alcohol results in decreased life satisfaction in both communities. On the other hand, there is no connection between life satisfaction and tobacco or marijuana use. The implications of these findings for educational prevention policies and decision-making were discussed.
\end{abstract}

\section{Keywords}

Life Satisfaction, Cross Cultural, Risk Behavior, Categorical Regression

\section{Introduction}

The exact meaning of the concept of life satisfaction is still disputable mainly due to its cross-disciplinarity, being a study subject for psychologists, sociologists, economists etc. The concept is used with reference to the subjective evaluation of overall quality of life in general (Diener \& Diener, 1995). Therefore, life satisfaction refers to the degree to which a person assesses the overall quality of his life as-a-whole in a positive way (Veenhoven, 2009). Broadly speaking, life satisfaction is linked to happiness and the achievement of the good life and, on 
the opposite side, to depression and unhappiness (Proctor et al., 2009). Assessing the level of one's life satisfaction therefore means that a person carries out a global evaluation of the life (Pavot et al., 1991), including satisfaction with the past, satisfaction with the future and other different views of life (Diener, Suh, Lucas, \& Smith, 1999; Diener \& Seligman, 2002). On the other hand, youth' life satisfaction is highly influenced by their perception that they can control their lives (Huebner et al., 2001).

Regardless of the definition, life satisfaction is considered a key component to develop positive mental health and it is an important determinant of many life outcomes (Proctor et al., 2009; Proctor et al., 2017). There is a wide range of factors affecting life satisfaction, including demographics, personality, physical health, socioeconomic status, social relationships, environment, risk-taking behavior, psychophysiological problems, character strengths, psychopathology etc. (Proctor et al., 2009; George \& Clipp, 1991). Moreover, there are a lot of risk factors associated with substance use by youth. On the other hand, it is not known enough the effects of using the alcohol, tobacco and marijuana by adolescents.

This research was focused on assessing the relationship between life satisfaction and behavioral risky acts in youth. The aim was to investigate how this relationship may differ or be similar across two groups from two different regions at NUTS 3 level: Frosinone area, in Italy, and Timis area, in Romania. The following questions were addressed in this study:

1) Is there a significant empirical relationship between life satisfaction and risk-taking behaviors such as alcohol, tobacco and marijuana use?

2) Are some of these specific risk-taking behaviors particularly predictive of adolescents' life satisfaction?

3) If yes, which are the specificities of these relationships across both cities?

4) Can relationships be interpreted as a causal relationship or is simply a spurious correlation?

According to the approach followed in this paper, life satisfaction was derived from three separate survey questions, as an assessment of the overall conditions of existence. The composite indicator was developed applying factorial analysis. In order to assess the association of life satisfaction levels with the prevalence of risky behaviors, a regression model was developed.

The paper is then structured as follows: Section 2 contains a review of the literature on the relationship between life satisfaction and risky behaviors; Section 3 contains a discussion about the data and methods used; in Section 4, results are presented and discussed; in Section 5, conclusions are drawn.

\section{Literature Review}

Despite the broad interest and extensive literature on adult life satisfaction, research about life satisfaction in youth has been developed more recently. Moreover, the relationship between youth life satisfaction and risk behavior has not 
been fully explored yet.

When Topolski et al. (2001) studied whether there could be a relationship between self-perceived quality of life and certain risk behaviors, the results of their study showed that the highest quality of life is mainly associated with a low engagement in risk-taking behaviors like tobacco, alcohol or illicit drug use. Therefore, youth engaged in the above-mentioned risk-taking behaviors reported a low quality of life and those who were engaged in many of them had even lower quality of life compared to those who engaged in only one health-risk behavior.

The same conclusions were also reached in other research (Zullig, Valois, Huebner, Oeltmann, \& Drane 2001; O’Donohue, Ferguson, \& Naugle, 2003; Kuntsche, Rehm, \& Gmel, 2004), in which life satisfaction is negatively correlated with smoking, cocaine, marijuana and alcohol consumption in youth. In addition to that, some research (Oladipo et al., 2013) shows that the negative life satisfaction score in youth is strongly associated with risky behaviors like physical fighting or carrying a gun (Piko et al., 2006). However, alcohol, cigarettes, and marijuana still are the most common and abused substances by youth (Mazur \& Woynarowska, 2004).

On the other hand, other researchers found that life satisfaction is positively associated with no smoking and other healthy behaviors but not related to alcohol consumption (Grant et al., 2009). In this research, a questionnaire was developed and administered to 17,246 students, aged 17 - 30 years from 21 countries for a large-scale research initiative also investigating alcohol consumption, including Western Europe and Central and Eastern Europe. Slightly differences were found on the two parts of Europe (65\% versus $60 \%$ ), but with similar patterns regarding smoking. In a similar way, a study on Malay youth (Mohamad et al., 2018) revealed "no significance relationship between life satisfaction and substance abuse". Massin \& Kopp (2011) found "a hump-shaped relationship" between life satisfaction and alcohol use and even a positive relationship between life satisfaction and alcohol consumption. Even though according to Diulio et al. (2014), low life satisfaction can be related to alcohol abuse in college students, there is actually no direct evidence of a relationship between life satisfaction and alcohol consumption (Murphy et al., 2005), but only different nonlinear relationships (Alati et al., 2005; Skogen, Harvey, Henderson, Stordal, \& Mykletun, 2009).

Specific research carried out more recently in Australia (Fischer et al., 2015) revealed that poor life quality can be associated with early-age alcohol consumption in adolescents and young adults. In Europe, according to a research involving a sample of 1383 Swedish adolescents, aged 12 to 13 , showed a negative correlation between self-reported emotional and behavioral problems and self-rated well-being in relation to alcohol experiences (Boson et al., 2016). Kuntsche et al. (2004) investigated alcohol abuse in Swiss adolescents and found that consumers who have a lower level of life satisfaction are more likely to suffer from depression and have a history of bullying and hitting. 
The results of a study carried out by the University of Cassino and Southern Lazio (Ferrara et al., 2006) on the lifestyle of young people in the province of Frosinone shows that $59.3 \%$ of the participating students, who were all from schools located in the province of Frosinone, declare to regularly drink alcoholic beverages. The main drinks that they consumed were hard drinks (78.9\%), wine (71.4\%), cocktails (66.8\%), beer (63\%). The study also found that the presence in the household of both parents who drink alcoholic beverages is a risk factor for developing this habit, which is influenced mainly by the behaviour of the father. The main reasons listed leading to the consumption of alcoholic beverages were the following: feeling like an adult (94.4\%), for fun (90.6\%), need to socialize (91.5\%), to escape (86.9\%) and for enjoyment (73.1\%). Additionally, 35.4\% of the sample were smokers ( $60 \%$ women, $40 \%$ men), who started smoking at the average age of 15.7 years with $31 \%$ of the students reported to smoke up to 10 cigarettes a day. Being female (7.6\%) and a student (58.4\%) seems to increase the probability of not being able to abandon this habit. Motivations preventing female student from smoking are mainly precocious aging (95.4\%), the awareness of the harm to health caused by it (93.8\%), and sterility (93.7\%). In addition, $17 \%$ of the students declare they took drugs, starting at an average age of 15.7 and $77.6 \%$ of them are smokers, with statistically significant differences between the sexes. The use of psychotropic substances is widespread even among those who consume alcohol. In relation to the type of drugs used, $34.7 \%$ of the students reported to make use of cannabinoids. They are primarily at-risk male students attending a public technical secondary school. With reference to motivations leading to drug addiction, $76.7 \%$ showed the need to feel like an adult, need for imitation $60.2 \%$ and finally the pleasure of the "forbidden fruit". $70.7 \%$ of the entire sample know or have relations with people who make use of drugs.

The prevalence of substance use in youth often varies according to demographic characteristics such as gender, age, and socioeconomic status. The first experience with drugs mainly happens during adolescence and, due to the early age of initiation, it is generally characterized by the use of soft drugs. Knowledge, as showed by the results, does not mean a greater awareness in preserving one's own health. This study confirms what found by previous research, as the medium-high level of education of parents in relation to consumers does not seem to be a protective factor against the exposure to drugs (Scafato et al., 2003).

Highlighting the social impact of substance use (licit or illicit), the European Union Drugs Strategy 2013-20202 recommends the improvement of "coordination, international cooperation and information sharing, monitoring, research and evaluation". The social risks of these substances and long-life impact have been not yet fully understood and constant research is required.

\section{Data and Methods}

\section{The Regions and the samples}

The data was collected through two separate surveys, one conducted in Frosi- 
noneprovince and another one in Timis province. The same questionnaire was used. The questionnaire was aimed at measuring the levels of the life satisfaction and smoking, alcohol and drug consumption in youth. Data was compared to highlight the distinct determinants. The size of the samples was 509 in Frosinone and 526 in Timis. The population was represented by individuals aged between 15 to 20 . The underlying assumption was that most of the individuals aged between 15 and 20 are enrolled in secondary school or university. Thus, respondents were selected through schools. Stratified samples were used that reflected the distribution of the schools in Frosinone and Timis. The demographics of the samples generally matched for both cities. The inclusion of these two cities is based on some demographic similarities and on community and labor market dissimilarities. The age and sex distribution of the samples are represented in $\mathrm{Ta}$ ble 1. It can be noticed that, in terms of age and sex, there are no significant differences between the two samples.

Frosinone is a province with a population of about 493,067, while Timis's is around 698,201 (Eurostat, 2019a). Both provinces have academic cities (Cassino in Frosinone province and Timisoara in Timis province) but they are completely different with regard to the number of students. In Timis province there are four public and three private Universities, all located in Timisoara, totaling about 50,000 students. In Frosinone province, there is only one public University, located in Cassino, which has about 8000 students.

The two provinces have different employment patterns. The unemployment rate is $16.6 \%$ in Frosinone province, much more above the national average, which is $9.7 \%$. The employment rate is $48.7 \%$, which is unequally divided by gender ( $60.3 \%$ of employed men and only $37.1 \%$ of women). Youth unemployment is $47.46 \%$. The NEETs (15 - 29 years) in Frosinone province are $31.13 \%$. The lowest levels of employment are recorded in the south part of the province, where the city of Cassino is located. Italy is the country in the European Union with the highest percentage of young NEETs (not in employment, education, or

Table 1. Age and sex distribution.

\begin{tabular}{|c|c|c|c|c|c|c|c|}
\hline \multicolumn{4}{|c|}{ Frosinone $(\mathrm{N}=509)$} & \multicolumn{4}{|c|}{ Timis $(\mathrm{N}=526)$} \\
\hline Age & $\%$ & Sex & $\%$ & Age & $\%$ & Sex & $\%$ \\
\hline \multirow[b]{2}{*}{$15-16$} & \multirow[b]{2}{*}{46.1} & M & 19.3 & \multirow[b]{2}{*}{$15-16$} & \multirow[b]{2}{*}{38.2} & $\mathrm{M}$ & 22.1 \\
\hline & & $\mathrm{F}$ & 26.8 & & & $\mathrm{~F}$ & 16.1 \\
\hline \multirow{2}{*}{$17-18$} & \multirow{2}{*}{41.9} & M & 21.1 & \multirow{2}{*}{$17-18$} & \multirow{2}{*}{49.2} & $\mathrm{M}$ & 22.9 \\
\hline & & $\mathrm{F}$ & 20.9 & & & $\mathrm{~F}$ & 26.3 \\
\hline \multirow[b]{2}{*}{$19-20$} & \multirow[b]{2}{*}{11.9} & M & 5.2 & \multirow[b]{2}{*}{$19-20$} & \multirow[b]{2}{*}{12.7} & $\mathrm{M}$ & 6.8 \\
\hline & & $\mathrm{F}$ & 6.8 & & & $\mathrm{~F}$ & 5.8 \\
\hline \multirow{2}{*}{\multicolumn{2}{|c|}{ Total }} & M & 45.5 & \multirow{2}{*}{\multicolumn{2}{|c|}{ Total }} & $\mathrm{M}$ & 51.8 \\
\hline & & $\mathrm{F}$ & 54.5 & & & $\mathrm{~F}$ & 48.2 \\
\hline
\end{tabular}

${ }^{a} \mathrm{~N}-$ number of participants. 
training). One Italian out of four (24.1\%) aged between 15 and 29 does not work, study, or train against $17.8 \%$ of young Romanians. The EU average is $13.4 \%$. (Eurostat, 2019b).

On the other hand, Timis has one of the lowest unemployment rates in Romania, only $1 \%$, against a national average of about $4.3 \%$. The employment rate is about $73.1 \%$ (2017), with a high gender gap (78.7\% of men employed against $67.1 \%$ of women). Youth unemployment rate is about $21 \%$. The NEETs rate is below Frosinone's, about 11\%.

In terms of GDP per capita, Frosinone province shows a a worse situationthan Timis. In 2017 (Eurostat, 2019c), GDP per capita was 21,900 euro in Frosinoneprovince and 22,900 euro (PPS, 2017) in Timis. However, it should be highlighted that Timis is above the national average (16,900 euro PPS per capita, national level) while Frosinone is below then Italian national average (27,600 euro PPS per capita, national level) (Eurostat, 2019c).

However, taking into account all these similarities (e.g. level of GDP per capita) and differences (e.g. unemployment rate) between the two regions, a comparative research could be valuable in order to understand the specificities of the relationship between life satisfaction and risk behaviors.

\section{Dependent variable}

The focus of the research is to assess the relationship between life satisfaction and risk behaviors. Life satisfaction was our dependent variable. According to the approach adopted in this paper, life satisfaction was considered synonymous with happiness or subjective well-being, defined as the degree to which an individual assesses the overall quality of his life as a whole in a positive way (Veenhoven, 2009).

Life satisfaction was measured based on the following items:

1) How satisfied are you with your life in Frosinone/Timis?

2) Do you think your life is easier or harder than your parents'?

3) Would you like to live in the same place in future?

As general satisfaction with life, perception of one's own life compared with parents and the wish to stay in the same place are theoretically intertwined variables, we decided to build a composite indicator separately before making any further analysis.

The items were grouped into a single variable through dimension reduction. The Categorical Principal Components Analysis (CATPCA) was used. This is implemented in the Categories module of SPSS. CATPCA is a multivariate technique developed to analyze categorical variables (Van Der Kooij et al., 2006). This is an implementation of the optimal scaling approach to Nonlinear Principal Components Analysis (NLPCA).CATPCA is similar to traditional PCA, but it is designated for variables of mixed measurement level, possibly nonlinearly related to each other.

Two CATPCA analyses were carried out with two components using different scaling levels: ordinal and spline ordinalscaling levels. In terms of PVAF and 
Cronbach's alpha, the spline ordinal solution turned out to be a more appropriate approach for this type of data. Table 2 shows the results of the CATPCA analysis for Frosinone province. It contains the percentage of variance accounted for by the component (PVAF), the eigenvalues (VAF) and the Cronbach's alpha after carrying out the CATPCA with two components with spline ordinal scaling level. The one-dimension component fits well the data having an eigenvalue higher than 1 and Cronbach's alpha by 0.822 , explaining about $73 \%$ of the variance. Thus, only the first principal component was retained in the analysis. The object scores were saved and used as a new dependent variable for further analyses. The results of CATPCA analysis for Timis are shown in Table 3. The one-dimension component fits well the data having an eigenvalue higher than 1 and Cronbach's alpha by 0.825 , explaining about $74 \%$ of the variance. As in the case mentioned above, only the first principal component was retained in the analysis. The object scores were saved and used as a new dependent variable for further analyses.

\section{Independent variables}

Risk behaviors were measured using three separate questions. The abuse of alcohol was measured through an item asking the participants "In the last weeks, how many times did you use alcohol?". Responses were categorized as " 1 -every day", "2-three-four times per week", "3-only on Saturday evenings" and " $4-\mathrm{I}$ do not drink". From this, a dummy variable was created indicating whether the participants drinkalcohol (coded 1) or do not drink it (coded 0). Marijuana use was measured by asking participants "Haveyou ever used marijuana in your lifetime?". Similarly, smoking behavior was measured by asking "Have you ever smoked tobacco?".

The descriptive statistics of the variables are presented in Table 4.

Table 2. Summary of nonlinear principal components analysis (Frosinone).

\begin{tabular}{cccc}
\hline \multirow{2}{*}{ Dimension } & \multicolumn{3}{c}{ Variance Accounted For } \\
\cline { 2 - 4 } & Cronbach's Alpha $^{\mathrm{a}}$ & Total (Eigenvalue) & \% of Variance \\
\hline 1 & 0.822 & 2.213 & 73.767 \\
2 & 0.590 & 1.648 & 54.932 \\
Mean & $0.723 \mathrm{a}$ & 1.930 & 64.350 \\
\hline
\end{tabular}

amean Cronbach's alpha is based on the mean eigenvalue.

Table 3. Summary of nonlinear principal components analysis (Timis).

\begin{tabular}{cccc}
\hline \multirow{2}{*}{ Dimension } & \multicolumn{3}{c}{ Variance Accounted For } \\
\cline { 2 - 4 } & Cronbach's Alpha $^{\mathrm{a}}$ & Total (Eigenvalue) & \% of Variance \\
\hline 1 & 0.825 & 2.221 & 74.030 \\
2 & 0.524 & 1.537 & 51.228 \\
Mean & $0.702^{\mathrm{a}}$ & 1.879 & 62.629 \\
\hline
\end{tabular}

${ }^{a}$ mean Cronbach's alpha is based on the mean eigenvalue. 


\section{Data analysis}

First step consisted of computing frequency distributions. They were calculated to examine the distribution of the variables in both samples. Table 5 displays the frequencies of each risk-taking behavior. It can be noted that the use of alcohol is higher in Frosinone sample, with about 20-percent difference between Timisoara's and Frosinone's samples. Another important difference between Frosinone (Italy) and Timis (Romania) was found regarding the use of tobacco. On the other hand, data were similar with regard to the use of marijuana.

In the next step, a regression model was used to determine whether a significant relationship existed between life satisfaction and the use of alcohol, tobacco and marijuana. The analysis was carried out separately for each sample. As a model we choose a multiple categorical regression with optimal scaling (CATREG). The model was employed using SPSS Statistics software package. CATREG is a nonparametric method which can perform multiple regression with categorical or a mix of numerical and categorical variables. Due to this, it has recently been drawing the attention of researchers from social and behavioral sciences (Beamish, 2006). CATREG is designed to allow nonlinear transformations of the variables, including the response variable. Moreover, according to Van Der Kooij et al. (2006) it "can be used with numerical data to explore the existence of nonlinear relationships".

Regression results suggest that exposure to alcohol lead to the decrease of life satisfaction in both communities. On the other hand, there was no found any connection between life satisfaction and tobacco or marijuana use. The next section presents in more detail the results of regression analysis.

\section{Results and Discussions}

The results of this study suggest that the amount of variance in life satisfaction

Table 4. Descriptive statistics.

\begin{tabular}{ccccccc}
\hline \multirow{2}{*}{ Lot/Variable } & \multicolumn{3}{c}{ Frosinone $(\mathrm{N}=509)$} & \multicolumn{3}{c}{ Timis $(\mathrm{N}=526)$} \\
\cline { 2 - 7 } & Mean & $\mathrm{SD}$ & Median & Mean & SD & Median \\
\hline Alcohol & 3.352 & 0.7859 & 3.000 & 3.406 & 0.8956 & 4.000 \\
Tobacco & 1.419 & 0.5362 & 1.000 & 1.569 & 0.6039 & 2.000 \\
Marijuana & 1.6154 & 0.49614 & 2.0000 & 1.1835 & 0.38744 & 1.0000 \\
\hline
\end{tabular}

${ }^{a} \mathrm{SD}-$ standard deviation. ${ }^{b} \mathrm{~N}$-number of participants.

Table 5. Frequency of the risk-taking behavior.

\begin{tabular}{ccc}
\hline Type & $\begin{array}{c}\text { Frosinone }(\mathrm{N}=509) \\
\%\end{array}$ & $\begin{array}{c}\text { Timis }(\mathrm{N}=526) \\
\%\end{array}$ \\
\hline Alcohol & 54.0 & 36.7 \\
Tobacco & 19.3 & 4.2 \\
Marijuana & 2.0 & 2.7 \\
\hline
\end{tabular}

${ }^{\mathrm{a}} \mathrm{N}$-number of participants. 
scores in youth that can be attributed to the use alcohol is relatively small, albeit statistically significant. This research seems to confirm other international studies that proved that when two variables are related, the true relationship can be characterized by more than one possible association. For example, low levels of life satisfaction could be the cause for the use of substances, or the use of substances could affect the level of life satisfaction (Suldo \& Huebner, 2003).

In case of Frosinone, the multiple regression model with all three predictors produced $(\mathrm{F}(3,505)=3.558, p<0.014), \mathrm{R}^{2}=0.021$. Only the use of alcohol was found to be a significant predictor $(\beta=-0.126, p<0.009)$, while the use of tobacco use $(\beta=-0.050, p<\mathrm{ns})$ and marijuana use $(\beta=-0.025, p<\mathrm{ns})$ were not significant predictors. However, results show that both variables explain very little of the variance in life satisfaction. Table 6 summarizes the results of CATREG analysis referring to Frosinone province.

In case of Timis, the regression model with the same three predictors produced $(\mathrm{F}(5,522)=2.570, p<0.026), \mathrm{R}^{2}=0.024$. Alcohol use was a significant predictor $(\beta=-0.121, p<0.029)$. Both, marijuana use $(\beta=-0.015, p<\mathrm{ns})$ and tobacco use $(\beta=0.099, p<\mathrm{ns})$ are not significant predictor. However, it should be noticed that tobacco use is at the margin of statistical significance $(p<0.63)$. The results of CATREG analysis for Timis are summarizes in Table 7.

In both provinces, the use of alcohol was a significant predictor, indicating that the young people who drink alcohol are expected to have lower life satisfaction; on the contrary, the use of tobacco and marijuana are not significant predictors of life satisfaction. As the results show, the prediction for Frosinone and Table 6. Categorical regression coefficients (Frosinone).

\begin{tabular}{ccccc}
\hline Variables & $\beta$ & $\mathrm{SE}$ & F-value & Significance (p-value) \\
\hline Alcohol & -0.126 & 0.048 & 6.823 & $0.009^{\star *}$ \\
Tobacco & -0.050 & 0.079 & 0.405 & 0.525 \\
Marijuana & -0.025 & 0.061 & 0.167 & 0.683 \\
$\mathrm{R}^{2}$ & & & 0.021 & \\
F & & 3.558 & \\
\hline
\end{tabular}

adependent variable: life satisfaction. ${ }^{\mathrm{b}} \beta$ - unstandardized parameter estimation; SE-standard error for $\beta$; $\mathrm{R}^{2}$ - coefficient of determination; F-Fisher test. ${ }^{*} p<0.01,{ }^{*} p<0.05$.

Table 7. Categorical regression coefficients (Timis).

\begin{tabular}{ccccc}
\hline Variables & $\beta$ & SE & F-value & Significance (p-value) \\
\hline Alcohol & -0.121 & 0.064 & 3.557 & $0.029^{*}$ \\
Tobacco & 0.099 & 0.059 & 2.777 & 0.063 \\
Marijuana & 0.015 & 0.062 & 0.056 & 0.812 \\
$\mathrm{R}^{2}$ & & & 0.024 & \\
$\mathrm{~F}$ & & & 2.579 &
\end{tabular}

adependent variable: life satisfaction. ${ }^{\mathrm{b}} \beta$ - unstandardized parameter estimation; SE-standard error for $\beta$; $\mathrm{R}^{2}$ - coefficient of determination; $\mathrm{F}-$ Fisher test. ${ }^{* *} p<0.01,{ }^{*} p<0.05$. 
Timis $(\beta=-0.126$, respectively $\beta=-0.121)$ turns out to be similar with regard to the use of alcohol. This result appears to be only partially congruent with the principal findings from literature review.

The vast majority of the variance observed in the responses by secondary school students related to their life satisfaction scores could be attributable eventually to factors other than the use of illicit substances; those other factors however (e.g. social relationships, biased attitudes and beliefs, life circumstances) were not taken into consideration and investigated in the present study.

\section{Conclusion}

Knowledge of the level of life satisfaction in youth is very useful to predict whether and which health-risk behaviors young and very young people are likely to engage in (use of alcohol, tobacco, etc.) (Suldo \& Shaffer 2008). Young people who are dissatisfied with life are more inclined to adopt health-risk behaviors because they lack the ability to cope with and solve problems, which is necessary to manage stress and difficult situations. In particular, alcohol, which is considered a substance used to escape from reality, seems to be the only solution for them to solve their problems of dissatisfaction and overcome difficulties and discomfort (Mazur \& Woynarowska, 2004; Kliewer \& Murrelle, 2007).

The major finding of this study is that there are some similarities, in terms of risk behaviors and life satisfaction, between two communities that are completely different from an economic point of view. The analysis of three risk behaviors (alcohol, tobacco and marijuana use) in both communities showed that only the use of alcohol is a significant predictor for life satisfaction. Some studies that were included in the literature review suggest that all the risk behaviors mentioned are associated with life satisfaction scores. However, the evidence cannot be said to be very conclusive. It should be noted that, the direction of the relationship between substance use and life satisfaction is only speculative (Suldo \& Huebner, 2003). This research used a cross-sectional design which didn't allow determining how these variables affect each other: low life satisfaction precedes substance use or use of substances led to a low life satisfaction.

Furthermore, other studies observed the association between self-perceived quality of life and a variety of health-risk behaviors (Zullig et al., 2001). They found that young men who completely refrain from any risk behavior (e.g. use of tobacco, alcohol, or drugs) reported the highest quality of life compared to adolescents who occasionally or frequently engage in those behaviors (Lew et al., 2018).

Today, the early engagement in risk behaviors is a determining factor for health problems and their consolidation in adulthood and, when considering the results above, it is quite intuitive that effective health promotion interventions need to target at adolescents in the first place. It is therefore necessary to define a methodology allowing for a more careful structuring of the detection and monitoring techniques of the level of perception of life satisfaction and for the identi- 
fication of important information on attitudes that seem to have a strong impact on the adoption of risk behaviors (Ferrara et al., 2006). With regard to this, great attention needs to be paid to the activation of a real network of services and operating units in contact with research centers, with special attention paid to interventions through an integrated multidisciplinary approach.

As a broad result, this study bridges some gaps in the current literature and sheds some light on a population that deserves more attention. It does not provide generalized results about the relationships between life satisfaction and risk behaviors applicable to any country. On the contrary, it helps to understand why countries economically very similar differ in their levels of self-reported life satisfaction and happiness. Despite the small sample size and the low variance in some cases, the present study is to be considered a pilot study on the young population analyzed, thus representing the grounds to carry out a multicenter study.

\section{Conflicts of Interest}

The authors declare no conflicts of interest regarding the publication of this paper.

\section{References}

Alati, R., Lawlor, D. A., Najman, J. M., Williams, G. M., Bor, W., \& O’Callaghan, M. (2005). J-Shape or Linear Relationship between Alcohol Consumption and Depression: It Matters. A Response to Taylor \& Rehm. Addiction, 100, 872-873. https://doi.org/10.1111/j.1360-0443.2005.01102.x

Beamish, P. W. (2006). Publishing International (Joint Venture) Research for Impact. Asia Pacific Journal of Management, 23, 29-46. https://doi.org/10.1007/s10490-006-6114-Z

Boson, K., Berglund, K., Wennberg, P., \& Fahlke, C. (2016). Well-Being, Mental Health Problems, and Alcohol Experiences among Young Swedish Adolescents: A General Population Study. Journal for Person-Oriented Research, 2, 123-134. https://doi.org/10.17505/jpor.2016.12

Diener, E., \& Diener, M. (1995). Cross-Cultural Correlates of Life Satisfaction and SelfEsteem. Journal of Personality and Social Psychology, 68, 926-935. https://doi.org/10.1037/0022-3514.68.4.653

Diener, E., \& Seligman, M. E. P. (2002). Very Happy People. Psychological Science, 13, 81-84. https://doi.org/10.1111/1467-9280.00415

Diener, E., Suh, E. M., Lucas, R. E., \& Smith, H. L. (1999). Subjective Weil-Being: Three Decades of Progress. Psychological Bulletin, 125, 276-302.

https://doi.org/10.1037/0033-2909.125.2.276

Diulio, A. R., Cero, I., Witte, T. K., \& Correia, C. J. (2014). Alcohol-Related Problems and Life Satisfaction Predict Motivation to Change among Mandated College Students. Addictive Behaviors, 39, 811-817. https://doi.org/10.1016/j.addbeh.2014.01.001

Eurostat (2019a). Population on 1 January by Age Group, Sex and NUTS 3 Region. http://appsso.eurostat.ec.europa.eu/nui/show.do?dataset=demo $r$ _pjangrp3\&lang=en

Eurostat (2019b). Young People Neither in Employment nor in Education and Training by Sex, Age and Labour Status (NEET Rates).

http://appsso.eurostat.ec.europa.eu/nui/show.do?dataset=edat lfse 20\&lang=en 
Eurostat (2019c). Gross Domestic Product (GDP) at Current Market Prices by NUTS 3 Regions.

http://appsso.eurostat.ec.europa.eu/nui/show.do?dataset=nama 10r 3gdp\&lang=en

Ferrara, M., Gentile, A., Langiano, E., Elisabetta, D. V., La Torre, G., \& Walter, R. G. (2006). Alter Ego. Drug and Brain-Information to Prevent. Compared Analysis of Opinions, Knowledge and Habits among a Multicentric Sample of Secondary School Students about Drug Addiction. Journal of Preventive Medicine and Hygiene, 47, 8-11.

Fischer, J. A., Najman, J. M., Plotnikova, M., \& Clavarino, A. M. (2015). Quality of Life, Age of Onset of Alcohol Use and Alcohol Use Disorders in Adolescence and Young Adulthood: Findings from an Australian Birth Cohort. Drug and Alcohol Review, 34, 388-396. https://doi.org/10.1111/dar.12227

George, L. K., \& Clipp, E. C. (1991). Subjective Components of Aging Well. Generations, $15,57$.

http://search.ebscohost.com/login.aspx?direct=true\&db=c8h\&AN=2009475872\&site=e host-live\&scope $=$ site

Grant, N., Wardle, J., \& Steptoe, A. (2009). The Relationship between Life Satisfaction and Health Behavior: A Cross-Cultural Analysis of Young Adults. International Journal of Behavioral Medicine, 16, 259-268. https://doi.org/10.1007/s12529-009-9032-x

Huebner, E. S., Ash, C., \& Laughlin, J. E. (2001). Life Experiences, Locus of Control and School Satisfaction in Adolescence. Social Indicators Research, 55, 167-183. https://doi.org/10.1023/A:1010939912548

Kliewer, W., \& Murrelle, L. (2007). Risk and Protective Factors for Adolescent Substance Use: Findings from a Study in Selected Central American Countries. Journal of Adolescent Health, 40, 448-455. https://doi.org/10.1016/j.jadohealth.2006.11.148

Kuntsche, E., Rehm, J., \& Gmel, G. (2004). Characteristics of Binge Drinkers in Europe. Social Science and Medicine, 59, 113-127.

https://doi.org/10.1016/j.socscimed.2003.10.009

Lew, D., Xian, H., Qian, Z., \& Vaughn, M. G. (2018). Examining the Relationships between Life Satisfaction and Alcohol, Tobacco and Marijuana Use among School-Aged Children. Journal of Public Health (Oxford, England), 41, 346-353. https://doi.org/10.1093/pubmed/fdy074

Massin, S., \& Kopp, P. (2011). Alcohol Consumption and Happiness: An Empirical Analysis Using Russian Panel Data.

Mazur, J., \& Woynarowska, B. (2004). Risk Behaviors Syndrome and Subjective Health and Life Satisfaction in Youth Aged 15 Years. Medycyna Wieku Rozwojowego, 8, 567583. http://www.ncbi.nlm.nih.gov/pubmed/15788860

Mohamad, M., Mohammad, M., Mat Ali, N. A., \& Awang, Z. (2018). The Impact of Life Satisfaction on Substance Abuse: Delinquency as a Mediator. International Journal of Adolescence and Youth, 23, 25-35. https://doi.org/10.1080/02673843.2016.1267021

Murphy, J. G., McDevitt-Murphy, M. E., \& Barnett, N. P. (2005). Drink and Be Merry? Gender, Life Satisfaction, and Alcohol Consumption among College Students. Psychology of Addictive Behaviors, 19, 184-191. https://doi.org/10.1037/0893-164X.19.2.184

O’Donohue, W., Ferguson, K. E., \& Naugle, A. E. (2003). The Structure of the Cognitive Revolution: An Examination from the Philosophy of Science. Behavior Analyst, 26, 85110. https://doi.org/10.1007/BF03392069

Oladipo, S. E., Adenaike, F. A., Adejumo, A. O., \& Ojewumi, K. O. (2013). Psychological Predictors of Life Satisfaction among Undergraduates. Procedia-Social and Behavioral Sciences, 82, 292-297. https://doi.org/10.1016/j.sbspro.2013.06.263

Pavot, W., Diener, E., Colvin, C. R., \& Sandvik, E. (1991). Further Validation of the Satis- 
faction with Life Scale; Evidence for the Cross-Method Convergence of Well-Being Measures. Journal of Personality Assessment, 57, 149-161. https://doi.org/10.1207/s15327752jpa5701 17

Piko, B. F., Keresztes, N., \& Pluhar, Z. F. (2006). Aggressive Behavior and Psychosocial Health among Children. Personality and Individual Differences, 40, 885-895. https://doi.org/10.1016/j.paid.2005.08.012

Proctor, C., Linley, P. A., \& Maltby, J. (2009). Youth Life Satisfaction: A Review of the Literature. Journal of Happiness Studies, 10, 583-630. https://doi.org/10.1007/s10902-008-9110-9

Proctor, C., Linley, P. A., \& Maltby, J. (2017). Life Satisfaction. In Encyclopedia of Adolescence (pp. 1-12). Cham: Springer International Publishing. https://doi.org/10.1007/978-3-319-32132-5 125-2

Scafato, E., Ghirini, S., Galluzzo, L., Gandin, C., \& Russo, S. M. R. (2003). L 'Alcol E I Giovani Un 'Analisi Dei Fattori Determinanti L'Abuso.

https://docplayer.it/11598962-L-alcol-e-i-giovani-un-analisi-dei-fattori-determinanti-labuso.html

Skogen, J. C., Harvey, S. B., Henderson, M., Stordal, E., \& Mykletun, A. (2009). Anxiety and Depression among Abstainers and Low-Level Alcohol Consumers. The NordTrøndelag Health Study. Addiction, 104, 1519-1529. https://doi.org/10.1111/j.1360-0443.2009.02659.x

Suldo, S. M., \& Huebner, E. S. (2003). The Role of Life Satisfaction in the Relationship between Authoritative Parenting Dimensions and Adolescent Problem Behavior. Social Indicators Research, 66, 165-195. https://doi.org/10.1023/B:SOCI.0000007498.62080.1e

Suldo, S. M., \& Shaffer, E. J. (2008). Looking beyond Psychopathology: The Dual-Factor Model of Mental Health in Youth. School Psychology Review, 37, 52-68. https://www.researchgate.net/publication/228656864

Topolski, T. D., Patrick, D. L., Edwards, T. C., Huebner, C. E., Connell, F. A., \& Mount, K. K. (2001). Quality of Life and Health-Risk Behaviors among Adolescents. Journal of Adolescent Health, 29, 426-435. https://doi.org/10.1016/S1054-139X(01)00305-6

Van Der Kooij, A. J., Meulman, J. J., \& Heiser, W. J. (2006). Local Minima in Categorical Multiple Regression. Computational Statistics and Data Analysis, 50, 446-462. https://doi.org/10.1016/j.csda.2004.08.009

Veenhoven, R. (2009). World Database of Happiness Tool for Dealing with the "Data-Deluge". Psychological Topics, 18, 221-222. http://worlddatabaseofhappiness.eur.nl

Zullig, K. J., Valois, R. F., Huebner, E. S., Oeltmann, J. E., \& Drane, J. W. (2001). Relationship between Perceived Life Satisfaction and Adolescents' Substance Abuse. Journal of Adolescent Health, 29, 279-288. https://doi.org/10.1016/S1054-139X(01)00269-5 